\title{
Seis catecismos en una década asombrosa
}

\author{
Prof. DR. Luis Resines Llorente \\ Estudio Teológico Agustiniano de Valladolid
}

Recibido: 30 de junio 2021

Aceptado: 28 de octubre 2021

Resumen: En el momento en que la Edad Media daba paso al Renacimiento, se produjo un fenómeno extraño al que no resulta fácil dar explicación: en los últimos diez años del siglo $\mathrm{XV}$, aparecieron en lugares diversos y sin conexión entre sí nada menos que seis catecismos absolutamente independientes entre sí. No se había producido algo así en toda la Edad Media, y solo se repitió con la explosión de catecismos de la segunda mitad del siglo XVI. Si no es por la inauguración de unos nuevos tiempos, no se entiende semejante coincidencia.

Palabras Clave: Alfonso de Cámara, Hernando de Talavera, artículos de la fe, Franciso Jiménez de Cisneros, Diego de Deza, Missale giennensis.

Abstract: In the last years of the Middle Age, when the Renaissance is coming, it happened that appears six new catechisms in ten years. All of them with absolute independence respect the others. There is no justification, but the new age, the Renaissance, make possible a new response to a new times. Six authors wrote his catechisms, with its roots in the past Middle Age, but opening to a new world, a new conception of the Christian life.

KEY wORDs: Alfonso de Cámara, Hernando de Talavera, articles of faith, Francisco Jiménez de Cisneros, Diego de Deza, Missale giennensis. 
¿Qué ha podido suceder en esa época para que en el transcurso de diez años (o poco más) hayan surgido seis catecismos?

No resulta fácil contestar con una respuesta sencilla, ni menos aún, breve. Pero las cosas no suceden siempre por casualidad, y vale la pena intentar una respuesta. Lo que no deja de ser cierto es que se trata de una década asombrosa. Hasta hace muy poco, tan solo conocía la mitad de los catecismos que indicaré. Desconectados unos de otros, y con un conocimiento incompleto, parece que nada llamaba la atención. En unos pocos meses he dado con otros tres catecismos rigurosamente contemporáneos.

La sorpresa ha surgido al poner en orden, en su debido lugar cronológico, el último de estos seis que he llegado a conocer, el de Diego de Deza. Entonces, y solo entonces, he caído en la cuenta de que en diez años, una cifra de seis catecismos no resulta nada despreciable sino todo lo contrario.

\section{Los catecismos}

Es preciso comenzar por presentarlos, atendiendo a la cronología.

El primero de esta década es un catecismo español de autor desconocido, que se escuda ficticiamente en santo Tomás de Aquino. Es manuscrito y se encuentra en la BNE, ms. 9567. Dispone de un título un tanto largo: Esta es la declaración del credo, la qual compuso santo Tomas de Aquino, dotor e frayre que fue de la orden de los pedricadores. Hasta hace muy poco resultaba desconocido ${ }^{1}$.

El segundo en orden cronológico es el que tiene como autor a Hernando de Talavera, impreso en Granada, en 1496, una vez que su autor fue nombrado arzobispo de la recién conquistada ciudad. Se titula: Breue doctrina y enseñança que ha de saber y de poner en obra todo xpiano y cristiana. En la qual deuen ser enseñados los moçuelos primero que en otra cosa. Ordenola Fray Hernando de talauera: primero arçobispo de la santa yglesia de Granada ${ }^{2}$. Fue impreso por Meinardo Ungut y Juan Pegnitzer, que se desplazaron de Sevilla a Granada para efectuar la impresión.

1 L. REsines, Un desconocido catecismo español del siglo $X V$, en "Estudio Agustiniano" 55 (2020) 409-470.

2 T. DE AzConA, El tipo ideal de obispo en la Iglesia española antes de la rebelión luterana, en «Hispania Sacra» 11 (1958) 52 modifica ligeramente el título, al citarlo así: «Men- 
Sigue a continuación el impreso incunable debido a la pluma de Alfonso de Cámara. Éste publicó una obra amplia con el título principal de Epitome seu tractatus de sacramentis; la segunda parte de la misma tiene otro título propio, Libellum de doctrina christiana, que es el catecismo propiamente dicho. Fue impreso en Sevilla en 1496, y forma parte de los fondos de la Biblioteca Nacional de España (BNE I-1064).

En cuarto lugar va el sinodal que Francisco Jiménez de Cisneros, arzobispo de Toledo, propuso para su diócesis en el sínodo celebrado en Talavera de la Reina en 1498. Las actas del mismo, impresas en Salamanca, Juan de Porras, 1498. también forman parte de los fondos de la misma biblioteca, que conserva varios ejemplares.

Igualmente incunable es el impreso que contiene el Catecismo de Diego de Deza. Es obligado detallarlo. Diego de Deza había nacido en Toro (Zamora) en 1444. Ingresó en los dominicos y fue enviado a estudiar a Salamanca, donde se graduó y más adelante llegó a desempeñar alguna cátedra universitaria. Nombrado obispo primero de Zamora y enseguida de Salamanca, fue trasladado a Jaén en un breve episcopado (1498-1500), para desde allí ocupar su nuevo destino en el de Sevilla, donde murió.

En el escaso tiempo de estancia en Jaén, mandó imprimir el Missale propio de la diócesis, labor que se llevó a cabo en Sevilla a cargo de los impresores Meinardo Ungut y Stanislao Polono, en 1499. En dicho misal, latino, se encuentra sin título propio un catecismo castellano, que ocupa los f. 258r a 261r. Tal catecismo no es original, sino que se inscribe en la serie de catecismos que siguieron repitiendo con muchas modificaciones el que había surgido en el lejano 1322 en el concilio de Valladolid³. El ejemplar se conserva en el Archivo Histórico Diocesano de Jaén, “Cod. Liturg. $4{ }^{\mathrm{o}}{ }^{4}$. Es el que ocupa el quinto lugar en esta serie.

cionaremos su Doctrina y enseñanza que ha de saber y de poner por obra todo cristiano y cristiana; en la cual han de ser enseñados los mozuelos primero que en otra cosa, que resulta un precioso catecismo de los rudimentos de la religión». Se puede observar que ha hecho desaparecer el calificativo de «breve», que figuraba al comienzo del mismo, y que responde a la realidad; L. Resines, La Breve Doctrina de Hernando de Talavera, Granada, Arzobispado de Granada, 1993.

3 L. Resines, El catecismo del concilio de Valladolid de 1322, Valladolid. Ed. L. Resines, 2003.

${ }^{4}$ En vías de publicación. 
El último, el sexto ejemplar, es un curioso catecismo al que le falta una parte inicial. Está integrado en la regla con la que se organizaba la vida y funcionamiento de una cofradía; concretamente, la cofradía de la Candelaria, que tuvo su actividad en Valladolid, en los últimos años del siglo XV y primeros del XVI. Es manuscrito de propiedad privada. El contenido del manuscrito está publicado y estudiado ${ }^{5}$, y más en detalle el contenido del catecismo ${ }^{6}$. Una regla de cofradía es el lugar más inopinado para encontrar un catecismo, pero los hechos son así, ya que formaba parte de las obligaciones de los cofrades estar bien informados del cristianismo que practicaban. La regla de la cofradía no tiene autor preciso, pero cabría esperar que el catecismo lo tuviera; quizá por la mutilación inicial no se conoce el nombre de su documentado autor.

\begin{tabular}{|c|c|c|c|c|}
\hline & Fecha & Lugar & Autor & Edición \\
\hline $\begin{array}{l}\text { 1. Declaración del } \\
\text { credo... }\end{array}$ & 1491 & $\begin{array}{l}\text { sin } \\
\text { especificar }\end{array}$ & desconocido & manuscrito \\
\hline 2. Breve doctrina... & 1496 & $\begin{array}{l}\text { diócesis de } \\
\text { Granada }\end{array}$ & $\begin{array}{l}\text { Hernando de } \\
\text { Talavera } \\
\text { Granada, }\end{array}$ & $\begin{array}{l}\text { Juan Pegnitzer } \\
\text { y Meinardo Ungut }\end{array}$ \\
\hline $\begin{array}{l}\text { 3. Libellum de } \\
\text { doctrina... }\end{array}$ & 1496 & $\begin{array}{l}\text { sin } \\
\text { especificar }\end{array}$ & $\begin{array}{l}\text { Alfonso } \\
\text { de Cámara }\end{array}$ & $\begin{array}{l}\text { Sevilla, Juan de Nurem- } \\
\text { berg, Thomas Glogner y } \\
\text { Magno Herbst }\end{array}$ \\
\hline $\begin{array}{l}\text { 4. Sinodal } \\
\text { Talavera de la } \\
\text { Reina }\end{array}$ & 1498 & Toledo & $\begin{array}{l}\text { Francisco } \\
\text { Jiménez de } \\
\text { Cisneros }\end{array}$ & $\begin{array}{l}\text { Salamanca, Juan de Po- } \\
\text { rras }\end{array}$ \\
\hline 5. Missale de Jaén & 1499 & $\begin{array}{l}\text { diócesis de } \\
\text { Jaén }\end{array}$ & Diego de Deza & $\begin{array}{l}\text { Sevilla, Meinardo Ungut y } \\
\text { Stanislao Polono }\end{array}$ \\
\hline $\begin{array}{l}\text { 6. Regla de la } \\
\text { cofradía... }\end{array}$ & $\begin{array}{c}\text { c. } \\
1500\end{array}$ & Valladolid & desconocido & manuscrito \\
\hline
\end{tabular}

5 V. Alonso-Cortés, Valladolid, labradores, mujeres y cofrades. Cofradía de la Candelaria, Valladolid, Ayuntamiento de Valladolid, 2010. (= Publicaciones Municipales, 36).

${ }^{6}$ L. Resines, El catecismo de la Regla de la Candelaria, Valladolid, Ayuntamiento de Valladolid, 2010 (= Publicaciones Municipales, 37). 
Una vez descritos los catecismos con rasgos genéricos, pero suficientes para situar cada uno de los documentos, es cuando la pregunta inicial cobra toda la fuerza: ¿Qué ha podido suceder, o qué motivo puede haber detrás de esta explosión de seis catecismos en una década? Manuscritos o impresos, surgidos en lugares diferentes, a iniciativa de un obispo o de un autor privado, respaldados por un sínodo o sin esa apoyatura, ... ¿qué hay detrás de todo esto?; ¿o acaso no hay nada que actuara como motor?

No resulta fácil dar con una respuesta. Es preciso ir paso a paso, siguiendo todas las pistas disponibles, para captar si por algún resquicio se deja ver el motivo que hizo posible esta floración en tan breve espacio de tiempo.

\section{Fechas}

Al examinar las fechas de sus respectivas apariciones, no hay que establecer una cadencia que vaya de uno a otro, como de causa a efecto, de manera que uno cualquiera hubiera determinado la aparición de algún esfuerzo similar por parte de otro autor.

Ni siquiera se puede pensar que el descubrimiento de América hubiese sido el factor que desencadenara la serie. Esto por doble razón: el primero de los catecismos consignados es anterior al descubrimiento. En ninguno de los posteriores al descubrimiento aparece siquiera de pasada alguna referencia a la conveniencia de llevar la fe cristiana a los habitantes del otro lado del océano. Era lógico que no hubiera ninguna alusión en el catecismo de 1491. Pero en los otros, especialmente en los más cercanos a nuestros días, se podía haber colado alguna frase que denotara que había un mundo entero, que se empezaba a conocer, y que desconocía a Jesús y su mensaje. Para el año 1499, y para el 1500, era suficiente conocido el novedoso hecho: Colón había culminado ya dos viajes, y en 1498 emprendió el tercero. La novedad ya no era tanta pues se había difundido como reguero de pólvora al retorno del primero (enero de 1493), y era de dominio público al finalizar el segundo (1493-1496).

Pero no hay ninguna repercusión en los catecismos analizados. 


\section{Lugares}

Dos de estos catecismos no están escritos pensando en algún espacio determinado, o al menos no consta así en sus textos: el manuscrito de 1491, y el de Alfonso de Cámara. Podrían ser utilizados en cualquier territorio, puesto que su enseñanza era susceptible de ser empleada por igual en todas partes. Lo anterior no quiere decir que la referencia a lugares concretos haga de los otros catecismos instrumentos exclusivos para un lugar. Tan solo el último tiene ese tono peculiar.

El de Hernando de Talavera, impreso en Granada y destinado a ser utilizado allí, es, con toda probabilidad, una reedición de lo que el mismo Talavera propusiera a sus diocesanos cuando fue obispo de Ávila, y ahora, en su nueva sede de Granada a raíz de la conquista, vio la utilidad de disponer de él para educar la fe cristiana.

El de Cisneros fue propuesto en el sínodo de Talavera de la Reina, de 1498, con la intención de que fuera empleado en el inmenso territorio del obispado de Toledo, o incluso más allá, en la archidiócesis de la que Toledo era metropolitana ${ }^{7}$. La característica de un documento sinodal como éste es que su promulgación entraña un imperativo para todos los que tenían la obligación de enseñar la fe en la jurisdicción correspondiente. Trataba de salir al paso de la permanente ignorancia religiosa por parte de los fieles (y de los curas).

El de Diego de Deza, inserto en el misal propio de la diócesis de Jaén, tiene como destinatarios directos a los curas de la diócesis, que eran quienes utilizaban el misal; indirectamente, su empleo tenía como finalidad facilitar a los curas la recitación o predicación a sus parroquianos ${ }^{8}$. Parece que podría suponérsele una cierta exclusividad, por estar inserto en el misal de la diócesis; pero no hay tal, porque el examen de su contenido señala que no hay nada peculiar, y, al contrario, hunde sus raíces en el catecismo que había surgido en el concilio legatino de Valladolid, de 1322, y que se había repetido con múltiples variantes y modificaciones en nume-

7 A. García (ed.), Synodicon Hispanum, Madrid, BAC, X, 2011, 751-754.

8 F. J. Martínez Rojas, La enseñanza de la catequesis en el Jaén del XVI, en $A c$ tualidad Catequética, (2020) nº.265, 75-94; J. RodríGuez Molina, Sínodo de Jaén de 1492, Jaén, 1981. J. MontiJano Jaén, en Diccionario de Historia Eclesiástica de España, 1220-1224 hace referencia al misal, aunque no al catecismo incluido en él. 
rosas diócesis españolas, sin que entrañara en ningún caso un uso específico'.

El último de la serie, en torno a 1500, es el único que tiene unos destinatarios exclusivos: los miembros de la Cofradía de la Candelaria, ubicada en Valladolid. Forma parte de la regla de esa cofradía, y es evidente que está concebido para el uso de los cofrades inscritos en ella. Pero no contiene una enseñanza tan particular que no pudiera ser asumida por cualquier cristiano, aunque no perteneciera a ella. La intención es que los cofrades supieran bien la doctrina cristiana, como preocupación interna de la pía asociación, sin que eso entrañara que se desentendieran de la ignorancia de los que no eran cofrades. Además, su contenido tampoco entraña ninguna enseñanza fuera de lo común.

Vinculados a Granada, Toledo, Jaén o Valladolid, los respectivos lugares donde se originaron estos catecismos no arrojan ninguna luz que permita sospechar una irradiación desde un lugar en particular hacia los otros; ninguno destaca por sí mismo con un brillo especial.

\section{Autores}

Forzosamente hay que dejar a un lado los dos textos anónimos, el catecismo de 1491, y el de la Regla de la Candelaria, ambos manuscritos, pero carentes de referencia a algún autor.

Los otros autores conocidos deben ser considerados en sí mismos. Está fuera de cuestión el prestigio que Hernando de Talavera tuvo en Granada, como hombre ejemplar, y testimonio de santidad, capaz de diálogo con las colectividades de judíos y moros. Su prestigio personal le hizo gozar el respeto y veneración de los habitantes de Granada: a los ojos de los cristianos era un varón evangélico, aunque la población de la recién conquistada ciudad dejara mucho que desear en la vivencia de su fe, con advenedizos, truhanes y fugados de otros lugares que se acogían a la oportunidad que se ofrecía ante ellos. A los ojos de judíos y musulmanes, Talavera era la garantía de que se cumplían los acuerdos de Santa Fe, según

9 El catecismo del concilio de 1322 pasó por tres etapas. La primera con un texto original breve, conciso; la segunda experimentó una ampliación notable; la tercera hizo posible una refundición de los dos textos anteriores, y es la que tuvo mayor difusión en el tiempo. 
los cuales se respetaban sus creencias y costumbres religiosas. Talavera cumplía esto escrupulosamente, proponía la fe cristiana, pero en modo alguno violentaba a quienes no querían convertirse.

Francisco Jiménez de Cisneros representa la antítesis. Era el hombre político que asesoraba a los Reyes Católicos y urgía la conveniencia de la unidad religiosa, y la extirpación de formas religiosas no católicas. Desde este ángulo, su disposición para la diócesis toledana era la de un obispo que estipulaba lo que era necesario a sus diocesanos; pero como consejero real él intervino para que el 31 de marzo de 1492 se decretara por provisión real la expulsión de los judíos, expulsión que se ejecutó, tras un breve plazo a fin de forzar la "conversión" o vender sus bienes ${ }^{10}$. También contribuyó a forzar las "conversiones" masivas de musulmanes, a raíz de la sublevación que se produjo en Granada el 18 de diciembre de 1500 y que se sofocó por imposición armada entre ese día y el día 23, con bautizos masivos. Su influjo como consejero real, como político y gobernante no respalda que su figura pueda considerarse la de un catequista para que su catecismo fuera un modelo a seguir. Más bien, se trata de una sencilla cartilla, con escasa originalidad, lo que no podía estimular a nadie a imitarla, ya que era un texto común, ampliamente repetido.

Por su parte, el letrado Alfonso de Cámara como hombre culto, redactó un texto catequético extenso, en latín no siempre fácil, con la vista puesta en la formación del clero ${ }^{11}$. Pero precisamente por su extensión, así como

${ }^{10}$ J. PÉreZ, Historia de una tragedia, Barcelona, Crítica, 1993, 133.

${ }^{11}$ No he dado con mucha información sobre Alfonso de Cámara: "Teólogo español, muerto en Viena en 1487. Sobresalió en varias controversias con los judíos y tuvo cátedra en diferentes ciudades austríacas. Figura en las obras de Nicolás Antonio" (Diccionario Enciclopédico Espasa-Calpe, 10,1068). Por su parte, Nicolás Antonio (Bibliotheca Hispana vetus, II, 336-337) indica: "Conquense. Nacido en la localidad de Viana, diócesis de Cuenca, es autor de Recolectio sive Brachiologio seu Epitome Sacramentorum sanctae matris Ecclesiae. Terminó esta obra nueve años antes de su edición, que efectuó con adiciones y notas marginales abundantes, juntamente con el librito titulado De doctrina christiana en Sevilla, en la tipografía de Juan Nuremberg en MCDXCVI, en 4\%". Es posible mejorar algo la imprecisión de N. Antonio sobre el lugar de nacimiento, cuando le llama conquense, natural de Viana en la diócesis de Cuenca. En la actual provincia de Guadalajara hay dos, Viana de Jadraque y Viana de Mondéjar; la segunda, Viana de Mondéjar, fue diócesis de Cuenca, y es su lugar de origen, mientras que la otra localidad estuvo integrada en la diócesis de Sigüenza. Nada aparece de su condición de sacerdote, pero su innegable formación teológica 
por el uso de formas refinadas de lenguaje, no siempre podía ser motor de irradiación para que otros tuvieran en cuenta sus enseñanzas. De hecho, su obra más notable es un tratado sobre los sacramentos, al cual se añadió a la hora de la edición impresa una enseñanza compendiada de la doctrina cristiana, bastante extensa. De estos seis catecismos, es el único redactado en latín, por lo que dejaba fuera de su radio de influencia a múltiples desconocedores del mismo, lo que equivalía a una parte no pequeña del clero.

Algo parecido sucede con el catecismo que Diego de Deza incluyó en el misal impreso para Jaén. En este caso, las formas latinas del misal ceden paso al texto castellano. Así los curas no tenían que verse obligados a traducirlo (si eran capaces), y la doctrina podía ser proclamada y acaso explicada al pueblo congregado para la misa dominical. Pero en este caso no hay ni que pensar en irradiación por el prestigio del autor, sino todo lo contrario, pues Deza se limitó a incorporar al misal un texto catequético que ya tenía a sus espaldas una amplia difusión, de la cual él mismo se benefició, sin tener que redactar un nuevo catecismo totalmente original.

Como se ve, tampoco es posible detectar que la valía y prestigio de alguno de estos catecismos, o de un autor determinado, provocara la aparición de otros cuantos en la misma década, con un cierto deseo de imitación de un modelo valioso.

\section{Fuente común}

Ni los acontecimientos, ni tampoco los diversos lugares en que surgieron estos catecismos, ni siquiera la influencia que pudiera emanar de alguno de estos personajes (los que son conocidos) aporta una explicación suficiente para que surgiera esa cantidad de catecismos en un breve período de años.

\footnotetext{
lo hace suponer. Por otra parte, si murió en 1487 en Viena, la obra aparecida en 1496 es póstuma, con los nueve años de distancia señalados por Antonio, y posiblemente alguno más, pues es mucha justeza completar la obra el mismo año de su fallecimiento. No hay datos sobre quién se hizo cargo de ella para editarla en Sevilla al menos nueve años después de fallecido el autor. El título que N. Antonio indica para la primera parte resulta en cierto modo inseguro, vacilante, así como el que ofrece para la segunda parte, ya que lo que figura en el impreso es Epitome seu Tractatus de Sacramentis, y la segunda parte consta como Libellum de doctrina christiana.
} 
Por otra parte, era preciso leerlos todos, uno a uno, por ver si aparecía algún denominador común que, con un enfoque nuevo o más valioso, sirviera de fuente de inspiración; una fuente tan poderosa que estuviera tras ellos de modo callado pero eficaz. Una vez hecha la lectura, de nuevo aparece la misma conclusión: la ausencia de una fuente soterrada que estuviera en la base de cada uno de los catecismos analizados.

Sí cabe sospechar de la existencia de algún lejano empuje; pero no es factible pasar más allá de las sospechas. El catecismo anónimo de 1491 anuncia ficticiamente que es obra de santo Tomás de Aquino, pero se trata del viejo recurso de poner el nombre de un autor reconocido para dotar de prestigio el texto. El análisis deja claro que la atribución es imaginaria y no hay que remontarse más allá que la reflexión del verdadero autor. También el último de estos catecismos, el de la cofradía de la Candelaria, hace una alusión de pasada al propio santo Tomás, pero se llega al mismo resultado. No hay que buscar en él lejanos manantiales.

El catecismo de Hernando de Talavera dispone de su propio esquema, que no se parece a ningún otro, y no permite barruntar de dónde ha podido recibir influencia alguna; quizá de nadie. Lo mismo sucede con el docto y bien razonado que escribió Alfonso de Cámara (en exquisito latín): no es posible percibir más criterio inspirador que el de su propio razonamiento, con vistas al fin que se había propuesto: ofrecer medios de formación a los nuevos curas.

En el caso del aprobado por Cisneros en el sínodo de Talavera, se trata de una simple cartilla de la doctrina, con formularios y enunciados, desprovistos de cualquier clase de explicación; son varias las cartillas existentes que presentan ese mismo contenido tan enteco, y las diferencias entre ellas solo se refieren al orden en que presentan los enunciados, o la inclusión de uno y la omisión de otro. Pero no hay nada que apunte a lejanas fuentes, ya que todo ello era patrimonio común de los cristianos. Por último, el de Diego de Deza, impreso para Jaén sí tiene unos hontanares lejanos, que se remontan al concilio de Valladolid de 1322. Lo que se señaló en aquel momento como contenidos de la fe que debían conocer los cristianos, sufrió diversas modificaciones, transformaciones, y, a lo largo de tres etapas distintas, surgió a la superficie en numerosos catecismos dispersos por lugares unas veces próximos entre sí y otras, distantes. El impreso para Jaén no es sino otro ejemplar más en la larga serie de catecismos que de allí proceden. 
Sin embargo, aunque hay una fuente que se percibe con claridad en el de Jaén, su influjo no es tan consistente como para que actúe y se perciba en los otros catecismos. Hay que aceptar, por consiguiente, que no hay un denominador común a todos ellos, que estuviera haciendo posible un florecimiento simultáneo.

\section{Los destinatarios}

Si se enfoca la cuestión desde los destinatarios a los que se dirigían los catecismos, cabría sospechar alguna coincidencia. Si los destinatarios fueran idénticos, sería posible dar con algún elemento común, aunque hubiera diferencias en la forma que cada uno lo llevara a cabo. Pero adelanto que tampoco en este punto es posible dar con algo más que el motivo genérico de transmitir la fe cristiana a unos o a otros.

En el orden de aparición, el catecismo de 1491 no precisa de modo explícito quienes son los destinatarios; solo es posible deducir por la lectura y análisis pausado que los destinatarios pueden ser los curas a los que se suministra un medio cualificado de formación para el desempeño de su labor pastoral.

El de Hernando de Talavera (1496) tiene como destinatarios al común de los cristianos, a los que enseña qué han de creer y rezar, cómo han de proceder en ciertos momentos (misa, Semana Santa, ...) y a los que indica algunas prescripciones muy básicas y elementales. Alguien podría pensar que lo escribió para los musulmanes presentes en Granada, pero no hay más que una frase breve que podría hacer una alusión a este colectivo ${ }^{12}$; y el resto deja ver claro que se dirige a cristianos viejos, para cimentar su fe.

El de Alfonso de Cámara tiene como destinatarios a los sacerdotes recién ordenados ("ad novellorum clericorum instructionem"). Es lo

${ }^{12} \mathrm{Al}$ presentar la señal de la cruz, el texto dice: "En el nombre del padre y del hijo y del spiritu sancto, un dios amen". Solo este indicio permitiría pensar en destinatarios procedentes del islam: tras presentar a las tres personas de la Trinidad, se afirma la unicidad divina con un dios. Esta misma afirmación aparece también en MARTín Pérez DE AYALA, Doctrina christiana en lengua arabiga y castellana (...) para instrucción de los nuevamente convertidos deste Reyno, Valencia, 1566. 
único que tiene en común con el catecismo de 1491; pero los desarrollos de estos dos catecismos no tienen ninguna semejanza, y el más antiguo no influye para nada en el más reciente.

El catecismo que propuso Cisneros en el sínodo de Talavera (1498) es una simple cartilla de la doctrina cristiana, que solo contiene formularios para que fueran aprendidos de memoria y así fueran repetidos. Coincide con el de Hernando de Talavera en los destinatarios, aunque Hernando de Talavera ofrece muchas más explicaciones que Cisneros; los caminos de estos dos catecismos siguen sendas bien distintas con esta única coincidencia.

El que Diego de Deza incluyó en el misal para Jaén (1499) está pensado para que los curas lo emplearan en la misa, a la hora de transmitir explicaciones algo extensas al pueblo. Celebrada en latín, la misa era interrumpida por la lectura en castellano de las enseñanzas del catecismo; facilitaba su labor la ventaja de disponer de todo ello en el mismo libro que los curas tenían sobre el altar. Indirectamente, pues, se dirigía al pueblo creyente; seguía la tradición peculiar en que es preciso insertar este catecismo.

Por último, el que se incluye en la Regla de la Candelaria (circa 1500) estaba pensado -rara excepción- para los cofrades que integraban la asociación. La propuesta era más ambiciosa que en otras muchas cofradías, ya que no se ceñían en exclusiva a la asistencia material de los necesitados, y al acompañamiento a los difuntos, sino que proponía que los cofrades no fueran misericordiosos pero ignorantes, sino personas bien enteradas de su fe, para que la llevaran a la práctica conociendo bien lo que realizaban.

Es posible comprobar que la gran carencia de formación en un amplio sector del pueblo cristiano impulsó a varios autores a redactar sus catecismos. Cierto que existía esa deficiente formación, o, dicho de otra forma más cruda, una ignorancia generalizada. El deseo de remediarla es algo que estimuló a los autores de estos catecismos. Pero no se percibe que un catecismo en concreto fuera el detonante que provocara la actuación de otro u otros autores

\section{Contenidos}

Tras haber recorrido los anteriores apartados a la búsqueda de algún vínculo común, de alguna influencia mutua, se abre paso la evidencia de 
que no parece existir lazo alguno que encadene unos catecismos con otros, y que cada uno parece haber salido a la luz pública a impulsos de los motivos independientes de los respectivos autores.

Por la misma razón, había que examinar los contenidos de cada uno de estos textos, por ver si entre sus expresiones de podían entrever afinidades. La forma más rápida y fácil de apreciar sus enseñanzas es condensar en un cuadro los tratados que abordan cada uno de estos catecismos:

\begin{tabular}{|c|c|c|c|c|c|c|}
\hline Contenidos & $\begin{array}{c}\text { Declaración } \\
1491 \\
\end{array}$ & $\begin{array}{c}\text { Talavera } \\
1496 \\
\end{array}$ & $\begin{array}{c}\text { Cámara } \\
1498 \\
\end{array}$ & $\begin{array}{c}\text { Cisneros } \\
1496 \\
\end{array}$ & $\begin{array}{l}\text { Deza } \\
1499 \\
\end{array}$ & $\begin{array}{c}\text { Candelaria } \\
\text { c. } 1500 \\
\end{array}$ \\
\hline Señal de la cruz & & $\mathrm{X}$ & $\mathrm{x}$ & $\mathrm{X}$ & & \\
\hline Padrenuestro & $\mathrm{X}$ & $\mathrm{x}$ & & $\mathrm{x}$ & $\mathrm{X}$ & \\
\hline Avemaría & & $\mathrm{x}$ & & $\mathrm{x}$ & & \\
\hline Credo & $\mathrm{X}$ & $\mathrm{x}$ & $\mathrm{x}$ & $\mathrm{x}$ & $\mathrm{x}$ & \\
\hline Salve & & $\mathrm{x}$ & & $\mathrm{x}$ & & \\
\hline Artículos de la fe & $\mathrm{X}$ & & $\mathrm{x}$ & $\mathrm{X}$ & $\mathrm{X}$ & $\mathrm{X}$ \\
\hline Mandamientos de Dios & $\mathrm{x}$ & $\mathrm{x}$ & $\mathrm{x}$ & $\mathrm{x}$ & $\mathrm{x}$ & $\mathrm{X}$ \\
\hline $\begin{array}{l}\text { Mandamientos de la } \\
\text { Iglesia }\end{array}$ & & $\mathrm{X}$ & & $\mathrm{X}$ & & \\
\hline Obras de misericordia & $\mathrm{X}$ & $\mathrm{x}$ & $\mathrm{x}$ & $\mathrm{x}$ & $\mathrm{x}$ & $\mathrm{X}$ \\
\hline Virtudes & & $\mathrm{x}$ & & & $\mathrm{x}$ & $\mathrm{x}$ \\
\hline Pecados capitales & & $\mathrm{x}$ & $\mathrm{x}$ & $\mathrm{x}$ & $\mathrm{x}$ & $\mathrm{X}$ \\
\hline Dones del Espíritu Santo & & & $\mathrm{x}$ & & & $\mathrm{x}$ \\
\hline Sacramentos & & $\mathrm{x}$ & $\mathrm{x}$ & & $\mathrm{X}$ & $\mathrm{x}$ \\
\hline Bienaventuranzas & & & $\mathrm{x}$ & & & $\mathrm{x}$ \\
\hline \multirow[t]{3}{*}{ Otros contenidos } & & Or. ángel & $\begin{array}{l}\text { Frutos } \\
\text { E.S. }\end{array}$ & & & \\
\hline & & Conducta & Sentidos & & & \\
\hline & & $\begin{array}{l}\text { Yo } \\
\text { pecador }\end{array}$ & & & & \\
\hline
\end{tabular}


Desde el primer vistazo se comprueba que los únicos contenidos comunes son los mandamientos divinos y las obras de misericordia. En todos los demás aparecen oscilaciones entre los que los abordan y los que no lo hacen. Llama la atención que algo tan básico como el padrenuestro, la oración por excelencia de los cristianos, no figure en todos los catecismos; se entiende porque algunos habían hecho la restricción de dejarlo para el aprendizaje doméstico, como ocurría también con el avemaría, el credo y la salve, las cuatro oraciones básicas.

No hay dos listas de contenidos que coincidan plenamente, o, con otras palabras, se seguía la tónica general en el medievo y también en el siglo XVI según la cual cada autor proponía en su texto lo que le parecía oportuno, sin que hubiera una guía externa a la que ajustarse.

Por otra parte, la sola contemplación del cuadro anterior no proporciona una idea exacta de lo que cada catecismo enseña. No es posible reproducir íntegros los textos completos de todos estos catecismos, pero sí es posible hacer un comentario, paso a paso, de cada una de sus partes, resaltando a la vez los aspectos más significativos cuando resulta procedente.

\section{Señal de la cruz}

El formulario solo está presente en tres catecismos. En el de Talavera (1496) se aborda con una cierta extensión, y se habla del signar y del santiguar como gestos complementarios, de cómo han de hacerse y de las palabras que hay que decir en cada momento. Además, al señalar cuándo ha de hacerse la cruz, se proponen algunas ocasiones (al levantarse, al comer,...) todas ellas con un marcado sentido personal, individual. En contraste con esta presentación, la mucho más amplia de Cámara (el mismo año 1496) señala que es un arma en manos del cristiano para repeler las asechanzas del demonio. Con marcado acento bíblico, recurre a bastantes textos de ambos testamentos en que se habla de la cruz (unas veces con sentido directo y claro, y otras forzando las frases hacia lo simbólico aunque no se refieran directamente a la cruz). En su larga presentación, también menciona las palabras que han de pronunciarse al hacer la cruz, y cómo se ha de realizar el signo. Pero destaca porque no se ciñe al empleo personal, sino que apunta al uso colectivo cuando recuerda que la cruz encabeza las procesiones, o que todos los cristianos la hacen como comu- 
nidad al comienzo de la lectura del evangelio de la misa. Además, mezcla las explicaciones sobre la cruz, signo del cristiano, con las explicaciones sobre el nombre mismo del cristiano, su origen y significado.

En tercer lugar, Cisneros (1498) aborda la cruz con el formulario escueto, latino, carente de toda explicación. Aprender esto resultaba más fácil, sin duda, por su brevedad, aunque no aparecen las explicaciones de los otros dos catecismos que presentan el signo de la cruz.

\section{Padrenuestro}

En el caso del padrenuestro, el catecismo de Cisneros (1498), como cartilla que es, se limita a ofrecer el texto escueto del padrenuestro (en latín, como otros formularios), sin explicación alguna, como también hace en castellano Talavera (1496), y, en contraste, el catecismo de la Candelaria (1500) ofrece una explicación original, y la Declaración (1491), otra diversa, mucho más detallada y profunda. Es suficiente este ejemplo para comprobar que el desarrollo que lleva a cabo cada catecismo de un mismo formulario u oración es siempre diverso, salvo cuando se trata de los formularios simples. Los otros catecismos no contemplan el padrenuestro, dado que se entendía en general como aprendizaje que se llevaba a cabo en el seno de la familia. Los que lo abordan son la excepción en la catequesis medieval: la oración tan sólo aparece en dos catecismos, ya que los otros dos son comentarios, que tratan de ir más allá de la simple recitación.

\section{Avemaría}

Igual que pasaba en el padrenuestro, son únicamente dos los catecismos que presentan la oración, escueta en ambos casos, porque se remitía al aprendizaje doméstico. Como era de esperar, son los mismos que presentan el padrenuestro sin comentarios: Talavera y Cisneros.

Los respectivos textos son así: Talavera: “Aue maria llena de gracia. El Señor contigo. Bendicta tu en las mugeres, y bendicta tu madre, y bendicto el fruto de tu vientre iesu. Virgen maria, madre de dios, ruega por nos peccadores. Amen". Y Cisneros: "Aue maria. Gratia plena, dominus tecum, benedicta tu in mulieribus. Et benedictus fructus ventris tui iesus. Virgo mater dei, ora pro nobis peccatoribus. Amen". 
En ambos casos, hay modificaciones. En la primera parte del avemaría el texto que ofrece Talavera introduce un inciso prácticamente desconocido: "bendicta tu madre", del que no tengo más noticia de que se usara así en los textos medievales; ni tampoco en el otro testigo de estos catecismos, que conserva al texto tradicional latino.

En la segunda parte de la oración, Talavera altera el usual "Santa María", por "Virgen María"; y Cisneros lo sustituye por el sencillo calificativo de "Virgo (Virgen)". En los dos casos, aparecen como testigos de que a finales del siglo XV aún no se había producido la añadidura final "ahora y en la hora de nuestra muerte".

\section{Credo y artículos}

A la hora de proponer al lector el compendio de la fe cristiana, unos catecismos se decantan por ofrecer el credo apostólico, en tanto que otros prefieren el formulario denominado los artículos de la fe; ambos constituyen una reduplicación y venían a decir lo mismo, aunque su enseñanza estuviera articulada siguiendo criterios diversos ${ }^{13}$.

En un caso, eran doce artículos que se asignaban por autoridad indiscutible a los propios apóstoles, y en el otro caso, en dos septenas, se contemplaban las afirmaciones sobre Dios y sobre la actividad de Jesús hecho hombre. A pesar de que se afirmaba -algunos de estos catecismos lo hacen- que enseñaban lo mismo y que no constituía problema, lo cierto es que sí lo suponía para el pueblo más sencillo, desconcertado por dos expresiones que no coincidían ni en el número ni en las frases con que se transmitía la $\mathrm{fe}^{14}$.

${ }^{13}$ L. Resines, Los artículos de la fe (Manuscrito del siglo XV), en "Estudio Agustiniano" 55 (2020) 631-665.

${ }^{14}$ La Declaración se expresa así en concreto: "[C]onuiene saber que estos articulos que en vna manera son doze en quanto son doze apostoles que los pusieron e son catorze en otra manera, en quanto los siete pertenesçen a la diuinidad e los siete pertenesçen a la humanidad de jhu xpo". Por su parte, el catecismo de la Candelaria, señala "Et estos quatorze articulos se contienen en el credo menor que fizieron los apostoles, pastores de santa eglesia, que es doctrina breue e tajada e necçesaria para todos los fieles xpianos que sepan que deuen creer para se saluar", y a continuación se esfuerza por armonizar ambas series de la mejor forma posible. 
Todavía es posible dar otro paso más, que muestra la disparidad -externa a la fe, sin duda- que existía a la hora de presentar el símbolo de la fe. En los casos en que presentan el llamado credo apostólico, la autoridad invocada de los apóstoles eliminaba de raíz toda sospecha de error; pero tres catecismos concretamente (tres de los aquí examinados, pues hay muchos más de otras fechas que incluyen la misma enseñanza) presentan de forma rotunda, incuestionable, cuál fue la frase que pronunció cada apóstol, basados en la leyenda que apuntaba a su origen. Resulta sorprendente el aplomo con que lo afirman, de manera que el lector ni siquiera podía albergar sospecha alguna. Hay tres catecismos que incluyen el credo apostólico así como los artículos de la fe. Pero he aquí que existen divergencias entre los tres, aunque podría esperarse que hubieran podido coincidir en este punto. Las asignaciones saltan de un apóstol a otro, y solo ahora, al contemplarlas en paralelo, se perciben los cambios:

\begin{tabular}{llll} 
Frase del credo & Declaración 1491 & Cámara 1496 & Cisneros 1498 \\
\hline Padre creador & Pedro & Pedro & Pedro \\
Jesús, el Hijo & Juan & Andrés & Andrés \\
Concebido por E. S. & Santiago mayor & Santiago mayor & Santiago mayor \\
Padeció, murió & Andrés & Juan & Juan \\
Descenso al infierno Felipe & Felipe & Tomás \\
Resurrección & Tomás & Tomás & Tomás \\
Ascensión & Bartolomé & Bartolomé & Santiago menor \\
Vendrá como juez & Mateo & Mateo & Felipe \\
Espíritu Santo & Santiago menor & Santiago menor & Bartolomé \\
Iglesia & Simón & Simón & Mateo \\
Perdón de pecados & Judas Tadeo & Simón & Simón
\end{tabular}

Es claro que ni los propios autores de cada uno de los catecismos consultaron siquiera lo que otros catecismos enseñaban, y, seguros como estaban de sus respectivas propuestas, con muy escasa diferencia de años, 
constatan enseñanzas diferentes; bien es verdad que se trata de algo ajeno a la propia fe, y en cada uno de los casos responde a un criterio recibido por diversas tradiciones, elaboradas para sustentar una leyenda. Tal leyenda a nuestros ojos aparece muy secundaria, pero estaba dotada de un notable peso para sustentar la valía de la fe, así como la del procedimiento por el que se aseguraba que se había formulado y transmitido.

El catecismo de 1491 (Declaración) presenta las frases del credo, asignadas a cada apóstol, y además muestra que cada una de estas afirmaciones tiene una conexión con alguna enseñanza bíblica, a la que da cumplimiento. Enseña que hay tres credos (el apostólico, el niceno y el atanasiano), y tras explicar el credo propone los artículos de la fe en forma abreviada.

Talavera (1496) se limita a proponer el texto del credo apostólico, sin ulteriores explicaciones. Al contrario, Alfonso de Cámara (en el mismo año 1496) organiza su explicación detallada sobre la base de los artículos de la fe, y solo al concluir se extiende al formulario del credo. De los doce artículos de la fe según los apóstoles, propone cada uno de ellos con una cierta brevedad, y lo hace con arreglo a unos versos medievales que denotaban cada asignación respectiva. Cámara también incide en el mismo aspecto que había llevado a cabo la Declaración de 1491, al mostrar que las frases de cada apóstol daban cumplimiento a las enseñanzas bíblicas con las que concordaban. Sin embargo, difiere de la enseñanza de la Declaración, al afirmar que los credos que existen en la Iglesia son cuatro, los tres ya indicados, más el que denomina "inocentiano o lateranense", compuesto en el concilio de Letrán, el año 1215, durante el papado de Inocencio III ${ }^{15}$.

En su catecismo, Cisneros, siempre conciso, no hace otra cosa que proponer en latín las frases del credo con la correspondiente asignación a uno u otro apóstol.

${ }^{15}$ El Catecismo cesaraugustano, del s. XIII, también señala la existencia de cuatro credos: "Quis [fecit] quartum? Innocentius IIIus in concilio generale" (= ¿Quién hizo el cuarto? Inocencio III en el concilio general). (Ver P. GALINDO, El breviario y ceremonial cesaraugustanos, en «Estudios Eclesiásticos de Aragón», II, 1930, cap. V, 99-104; ID., El catecismo cesaraugustano, en «Revista Zurita» III (=Homenaje a Finke) (1935) 122-128; L. RESINES, Historia de la catequesis en Aragón, en Centro Regional de Estudios Teológicos de Aragón, 2000 años de cristianismo en Aragón. VI Jornadas de Teología en Aragón, Zaragoza, Centro Regional de Estudios de Aragón, 2000, 61-211. 
Además de los tres catecismos que proponen el doble formularios, el catecismo de la cofradía de la Candelaria (1500), enseña tras los artículos, simplemente enunciados, que, como doctrina "cierta y necessaria", se corresponden con las frases del credo; para ello desgrana el credo y muestra con qué artículo concuerda cada una de las frases de los artículos, para que pudieran confrontarse los dos formularios.

\section{Salve}

Igual que había ocurrido con el avemaría, los dos únicos catecismos que se ocupan de la salve son los de Talavera, y Cisneros, aunque el primero en castellano y el segundo en latín. Se aprecia una ligera diferencia en la respectiva enseñanza, pues el de Talavera, al final de la oración dice: “... o clemente, o pia, o dulce virgen maría, ruega por nos sancta madre de dios”, con lo que termina el recitado. En cambio, el texto latino de Cisneros cambia en estas frases: “...o clemens, o pia, o dulcis semper virgo maria. Ora pro nobis sancta dei genitrix, ut digni efficiamur promissionibus christi". Topamos así con la falta de uniformidad en este punto, pues las dos versiones son difundidas por los autores de estos catecismos con la idea de que fueran conocidas y repetidas por el pueblo cristiano. Representan distintos momentos de la evolución de la oración en sus afirmaciones finales.

\section{Mandamientos de Dios}

Es un tratado, junto con las obras de misericordia, abordado por todos los catecismos de esta década.

La Declaración (1491) los presenta con una cierta amplitud, y además abona su explicación con numerosas referencias bíblicas. Al menos es lo que se deduce de la primera impresión, que es bastante clara, y bastante completa (en sí misma, y por comparación con otros catecismos). Pero a base de dar vueltas y más vueltas queriendo precisar al máximo la enseñanza sobre los mandamientos, termina por complicarla: propone estos en latín y también en castellano; luego los de la primera tabla y los de la segunda; más adelante los mandamientos negativos y positivos, y la claridad inicial se difumina hasta el punto de presentarlos en seis formas diferentes, incluso con expresiones, a título de formularios, que no coinciden 
plenamente entre sí. Se podría decir que es completísimo, pero, a la vez, nada pedagógico.

Por su parte, el catecismo de Talavera hace una presentación breve, ahora en castellano, con alguna explicación complementaria en los mandamientos tercero y cuarto. Tras la exposición, sintetiza todos los mandamientos en la regla: "hazer a otros el bien que querriamos que hiziessen a nos, y no les hazer el mal que no querriamos que nos hiziessen". Esta regla remite a Mt. 7,12, aunque el texto bíblico sólo muestra la primera mitad, la positiva, y no incluye la segunda, negativa.

Alfonso de Cámara dedica al tema el capítulo sexto, y lo comienza con un verso recapitulativo de corte medieval, en realidad una estrofa. Hace al principio una explicación de los mandamientos en general muy minuciosa, y pasa a detallar cada uno, aunque sigue la literalidad de los versos que ha empleado, a la que añade, en un segundo momento, el enunciado bíblico de cada mandamiento. Acorde con la tónica de toda su obra, hay abundancia de referencias bíblicas, a las que acompañan otras muchas referencias a autoridades de teólogos, para corroborar su exposición. Condensa la enseñanza de los mandamientos en la intervención de Jesús al compendiarlos en el amor a Dios y al prójimo (Mc. 12, 22).

La forma de cartilla por la que optó Cisneros determina que se limite a presentar la simple enumeración de los mandamientos, en castellano, sin ninguna explicación adjunta. Por su parte, el catecismo promovido por Diego de Deza propone los enunciados de cada uno de los mandamientos, en castellano; tales enunciados no son simple traducción del texto del libro del Éxodo, y en algunas ocasiones el mismo enunciado incluye alguna enseñanza incorporada al mandamiento; en cada uno de los casos, a la proposición del enunciado siguen unas posibilidades de cometer pecado por transgresión. Inserto en la corriente que venía del lejano concilio de Valladolid de 1322, es fiel a esa tendencia, aunque no se corresponda con las de los catecismos contemporáneos.

Por último, el de la regla de la Candelaria, hacia 1500, tiene una exposición fragmentaria, pues no se ha conservado lo correspondiente a los mandamientos primero y segundo y el inicio del tercero. Hace una síntesis que se parece a la de Alfonso de Cámara, aunque bastante más breve, y tampoco sigue el hilo de los versos recapitulativos. Una curiosidad es que en la explicación de los dos últimos mandamientos, que prohíben la codi- 
cia en los bienes ajenos, el mandamiento noveno se centra en los bienes inmuebles (casas, huertas, ...) y el décimo lo hace sobre los bienes muebles (ganados, caballerías, ...), y entre esos bienes muebles, está incluida también la mujer del prójimo, proposición ésta que hoy resulta llamativa.

El tratado de los mandamientos resulta en cierto modo central en estos catecismos examinados. Enseñan lo mismo en los mismos años, pero las diferencias abarcan una franja muy grande que va desde la simple proposición del formulario desnudo, a la justificación del mismo mandamiento con referencias bíblicas o de otros autores, pasando por la enunciación de posibles pecados.

\section{Mandamientos de la Iglesia}

Tras la presentación de los mandamientos divinos, cabría esperar que apareciesen los impuestos por la Iglesia, pero no sucede así exactamente. De los seis catecismos estudiados, tan solo dos hacen alusión a esto, y además de formas muy dispares. El catecismo de Cisneros (1498), como cartilla que es, se limita a una simple enumeración, como ocurre con otros enunciados. Y, con otro enfoque, el catecismo de Talavera (1496) se ciñe a una recomendación genérica, que ha de ser entendida como un llamamiento a la obediencia, no ceñida en exclusiva a las disposiciones eclesiásticas, sino también a las civiles. Dice así: "Obedecer e cumplir los mandamientos de los prelados e mayores ecclesiasticos e seglares e honrrarlos a cada vno en su estado". Con esta enseñanza global se pueden entender los mandamientos de la Iglesia, más otras muchas disposiciones que nada tendrían que ver con ella.

El resto de los catecismos analizados no dice nada sobre estos preceptos eclesiásticos.

\section{Obras de misericordia}

La formulación de las obras de misericordia es, junto con los mandamientos, el otro tratado que es contemplado en todos los catecismos. Tiene a sus espaldas una amplia tradición medieval y por consiguiente no resulta extraño semejante interés. 
En primer lugar, la Declaración de 1491 centra la atención en las obras de misericordia corporales y remite expresamente al pasaje del evangelio de Mt. 25, que reproduce, con lo cual muestra el apremio necesario para su cumplimiento. En un segundo momento continúa con las obras espirituales, y enseña que éstas son más importantes, de la misma forma que el alma es más importante que el cuerpo. Hay que entender que la práctica de las obras corporales tiene una apelación importante para todo cristiano, y que cuando se usaron estos catecismos las ayudas materiales constituían la seguridad social de la época, necesaria de todo punto para que muchas personas salieran adelante.

Talavera, por su parte, se limita a una afirmación genérica, breve, que no desmenuza las obras de misericordia, sino que las contempla con visión global, aunque hay una que estima más importante o más necesaria en su momento: "Cumple las obras de misericordia, que son socorrer a las personas en sus menesteres spirituales e corporales, e señaladamente corregir aparte caritatiuamente al que yerra".

En tercer lugar, Alfonso de Cámara dedica a esta cuestión el capítulo $14^{\circ}$ de su tratado. Parte, como suele ser habitual en él, de los versos medievales latinos que contemplan en síntesis estas obras de misericordia; tras el doble verso para unas y otras obras, las desarrolla con una cierta extensión cuando explica cada una de las dos series. Es más extenso que todos los demás catecismos.

Le sigue en orden Cisneros que se limita a la mera enunciación, dando por supuesto que son siempre entendidos los motivos y hasta dónde llegan las obligaciones de practicarlas en cada ocasión. Pero, por si no estuviera del todo claro, encuadra el recitado con una enseñanza al principio, que se diferencia de la simple enumeración, cuando dice: "Item es obligado todo christiano de obrar las obras de misericordia de que muy estrechamente nos ha de ser demandada cuenta el dia del juyzio".

En el caso del catecismo que publicó Diego de Deza, en quinto lugar, las obras de misericordia constan como último contenido del catecismo, con enumeración simple que apenas proporciona más que muy breves comentarios al enunciado escueto; primero presenta las corporales y luego las espirituales.

En último lugar, el catecismo de la Candelaria (1500) propone la enumeración más breve de los enunciados de cada obra. Pero el conjunto va 
precedido por una introducción que proporciona al lector el fundamento bíblico, aunque se reduzca solo a las obras corporales: "Siete son las obras de misericordia corporales. E siete son las obras de misericordia spirituales. Las corporales son estas, de las quales las seys dixo ihu xpo en el euangelio que daria omne cuenta en el dia del juyzio. Et estas pertenesçen al omne mientra tiene el alma en el cuerpo. La septima es tomada de tobias que soterraua los muertos e fuele contado por piedat, ca maguer que non pertenesçe al cuerpo después que el alma es fuera del, pero por que ha de ser ayuntado con el alma el dia del juyzio toda honrra que le fagan por reverençia del alma es contada por piedat e por obra de missericordia".

\section{Virtudes}

El tratado de las virtudes precisa una aclaración previa: se conocen como virtudes las tres que se denominan teologales (fe, esperanza y caridad), así como las cuatro llamadas cardinales (prudencia, justicia, fortaleza y templanza). Pero también se aplica el apelativo de virtudes -porque ciertamente lo son- a las actuaciones o los motivos que se enfrentan abiertamente a los pecados capitales. Para no mezclar los dos aspectos, en este momento solo abordo las que no tienen que ver con estos pecados; tales virtudes son contempladas en los catecismos de Cámara, Deza y Candelaria.

Alfonso de Cámara dedica un capítulo íntegro a las teologales, y otro más a las cardinales; ambas series son tratadas con mucha amplitud, con mucho detenimiento, partiendo, como suele ser habitual en él, de los versos recapitulativos que las compendiaban en latín. Los dos capítulos son tratados con numerosas referencias bíblicas, así como también las de otros autores que las habían estudiado.

El catecismo de Diego de Deza explica estas virtudes con unas definiciones amplias, que incluyen algunos matices destacados en cada caso. Hay una singularidad, pues a las dos series las denomina con los adjetivos de virtudes cardinales (usual) y divinales (que resulta fuera de lo común).

Más extraña es la forma que emplea el catecismo de la Candelaria para hablar de las dos series, puesto que se refiere a ellas como virtudes contemplativas (las teologales) que relaciona con las personas de la Trinidad; y virtudes activas (las cardinales), que impulsan a actuaciones concretas en la vida social del cristiano. A cada una de las que integran esta 
segunda serie, "que reglan al omne en todas las cosas temporales", después de definirlas, las subdivide en dos virtudes complementarias (emplea la expresión "que tiene dos ojos").

\section{Pecados capitales y virtudes contrarias}

Talavera presenta en su catecismo una definición breve de cada uno de los pecados capitales con la afirmación general de que "hase de guardar de caer en estos pecados". Pero no propone las virtudes contrarias a cada uno de ellos.

Alfonso de Cámara, rigurosamente contemporáneo, ofrece su enseñanza a lo largo de todo el capítulo séptimo sobre los siete pecados mortales (denominación usual para los que después se llamaron "capitales"); el capítulo siguiente, octavo, lo consagra a las virtudes contrarias a cada uno de ellos. En ambos casos recuerda los versos latinos correspondientes, que toma como punto de partida. Su exposición de los pecados capitales es muy amplia y minuciosa, y la de las virtudes que se les oponen es muy breve, lo que establece un desequilibro notable entre vicios y virtudes.

Cisneros se limita a la enumeración de los pecados, muy concisa, salvo en el caso de la pereza o acidia, en que se alarga con brevedad: "accidia que es pereza o negligençia de haber el bien que es obligado" ${ }^{16}$. Pero Cisneros concluye ahí, y no propone las virtudes contrarias a estos pecados, como hace Diego de Deza. Este se ciñe a la enumeración de los pecados y las virtudes opuestas a ellos, aunque no haya ninguna explicación ulterior ni de los unos ni de las otras.

Finalmente, el catecismo de la Candelaria, con una cierta extensión, presenta los pecados capitales, seguidos de las virtudes que se les oponen. Y aquí subdivide estas virtudes no en dos apartados (como hizo con las virtudes cardinales), sino en tres formas de llevarlas a cabo.

${ }^{16}$ En esta definición de la acidia, hay similitud con la que se encuentra en el catecismo de Diego de Deza: "accidia que quiere dezir pereza o negligencia de fazer el bien a que es tenudo"; en el castellano del siglo XV, "tenudo" equivale a "obligado". 


\section{Dones del Espíritu Santo}

Tan solo dos catecismos se ocupan de este formulario: el de Alfonso de Cámara, y el de la Candelaria. Alfonso de Cámara, fiel a su método, parte de unos versos iniciales, que no resultan nada comunes; a partir de ahí, lleva a cabo una explicación extensa, detallada, de los dones, cuya afirmación inicial -en la base de toda su concepción- es que estos dones sirven para rechazar los pecados capitales ("vitia"). Al contrario de esta presentación, el catecismo de la Candelaria se ciñe a una enumeración simple, que no contiene más que los nombres de cada uno de los dones.

\section{Bienaventuranzas}

Prácticamente había que repetir lo mismo para el caso de las bienaventuranzas, que no son propuestas más que por los mismos catecismos, el de Cámara, y el de la Candelaria. En la exposición de Cámara, la única diferencia reseñable respecto de otros tratados de su catecismo es que su exposición es bastante más breve que la de los dones del Espíritu Santo; además, en lugar de poner su atención en que se trata de enseñanzas evangélicas, como palabras del mismo Jesús, se dispersa en compulsar diversas fuentes para dilucidar si son siete u ocho.

El catecismo de la Candelaria ofrece otra perspectiva, pues presenta las bienaventuranzas como remedio contra los pecados capitales, a pesar de que no coinciden en número; en consecuencia, asocia las virtudes contra los pecados capitales, a las bienaventuranzas como una mayor capacidad de resistencia frente a las acometidas o tentaciones de los pecados.

\section{Sacramentos}

Para quienes leyeran la Declaración de la doctrina, el tratado sobre los sacramentos constituye una notable ausencia, que hace de este catecismo un catecismo incompleto. Nada se enseña sobre el tema.

La enseñanza que proporciona Talavera en su catecismo resulta enteramente desigual. Se sitúa en la perspectiva de lo que ha de hacer el cristiano, y proporciona unas pinceladas sobre lo que debe hacer cuando está 
en el templo y el respeto que debe mostrar a las especies eucarísticas; en esta misma línea habla de la conveniencia de recibir la comunión por viático, o la confirmación, o la unción de enfermos, sin que se perciba una enseñanza articulada sobre el conjunto de los sacramentos. Lo hace con mayor detalle cuando manifiesta las condiciones en que se debe recibir la comunión refiriéndose a la limpieza espiritual y corporal. Y de forma breve presenta la enseñanza básica sobre la penitencia, así como sobre el matrimonio. No se puede olvidar que el mismo Hernando de Talavera había escrito otros tratados sobre algunos sacramentos en particular, y, acaso por eso, es más breve en el catecismo ${ }^{17}$.

La enseñanza de Alfonso de Cámara en este punto es enteramente singular. La obra fundamental de Cámara es Epitome seu tractatus de sacramentis, con una extensión de 175 folios. En ella aborda con toda clase de detalles todos y cada uno de los sacramentos. Una vez concluida, a modo de segunda parte, sigue su Libellum de doctrina christiana, es decir, su catecismo, aquí examinado. Por consiguiente, después de haber expuesto minuciosa y detenidamente todo lo de los sacramentos, hace una exposición de la doctrina; pero, para que no se constara su omisión por parte de quien leyera solamente el catecismo, incluye el capítulo tercero: "de Ecclesiae sacramentis". Podía haber remitido simplemente a su exposición anterior, pero la duplica, y al ser un tema que domina con soltura, este capítulo sobre los sacramentos resulta el más extenso de todos los del Libellum de doctrina christiana. Como compendio de la primera parte, resulta más manejable, pero no hay duda que la presentación de los sacramentos es el tema principal en que se ha volcado para formar debidamente a los lectores de su obra, los curas noveles.

Causa sorpresa que Cisneros nada incluyera sobre los sacramentos. Tan sólo hay breves alusiones en otras enseñanzas, como en los mandamientos de la iglesia, por la obligación de confesar o comulgar anualmente; pero es una cuestión que no aborda.

En el catecismo incluido en el misal para la diócesis de Jaén, Diego de Deza se limita a repetir -como tributario que es de la corriente cate-

${ }^{17}$ Son obras de Hernando de Talavera: En que manera se deue haber la persona que ha de comulgar; Breue forma de confessar; y Siguese doctrina de la manera en que hauemos de restituyr y satisfazer qualesquier daño e males que a otros hayamos hecho. 
quética que procede del concilio de Valladolid- lo que decían los catecismos de esa tradición. Los trata con cierta calma, y pone la atención en el aspecto legal de los sacramentos al fijarse en cada uno de los extremos clásicos de materia, forma, ministro y sujeto que lo recibe; añade también el efecto que produce cada sacramento. Salvo variaciones en las expresiones (y alguna otra de una mayor importancia) se atiene a lo que se enseñaba en la serie de catecismos de esta corriente, sin tener en cuenta en absoluto lo que podían enseñar sus contemporáneos.

Finalmente, el catecismo de la Candelaria no presenta una exposición amplia de los sacramentos. Supera algo la simple exposición, porque tras los enunciados, se ocupa en señalar los sacramentos que son obligatorios en orden a la salvación, y los que son voluntarios; y también cuáles son los que se pueden recibir una sola vez y cuáles pueden reiterarse. Es bastante más que la explicación escueta.

\section{Otros aspectos secundarios}

Tras haber visto los más notables contenidos, y cómo son presentados de maneras bien diferentes en los catecismos analizados, hay que dejar constancia de algunos otros aspectos, de menor importancia aún, que solo son abordados por algún catecismo aislado, pero que solo aparecen una vez en toda la comparación: oración al ángel, conducta del cristiano en el templo, yo pecador, frutos del Espíritu Santo, sentidos corporales, cuándo se han de cumplir los votos o los juramentos, ... El mismo hecho de que no aparezcan más que una vez son muestra de su importancia menor, que ha hecho que varios autores no se hayan fijado en estos contenidos. Se trata simplemente de dejar constancia del hecho de las múltiples cuestiones que podrían ser abordadas.

\section{Desde la más absoluta independencia}

Tras examinar el contenido de estos catecismos, comparando cada uno de sus apartados, no he podido detectar que uno cualquiera de ellos haya influido en los posteriores a él para que sus enseñanzas quedaran reflejadas en otro u otros. No hay más remedio que llegar a la conclusión de que cada uno de los autores, por separado, llevó adelante su exposición 
de la doctrina, ajustándose al plan propio que se había trazado. Pero no hay más influencias. Todos los catecismos de esta década son plenamente independientes.

La variedad entre los seis es notable: dos son manuscritos (la Declaración, y el de la Candelaria), y el resto se publican impresos con el entonces reciente invento de la imprenta, buscando la mayor difusión. Tres son de iniciativa oficial de los respectivos obispos (Talavera, Cisneros, Deza), y los otros tres tienen carácter privado, por impulso personal. Uno (Cisneros) tiene entidad de cartilla, carente de explicaciones, y con formularios simples, mientras que los demás van acompañados de explicaciones, en ocasiones sencillas, y en otras muy elaboradas. Dos catecismos están destinados para la formación de los jóvenes curas (Cámara y Declaración), otros tres están pensados para el pueblo cristiano, bien directamente (Talavera y Cisneros), bien indirectamente (Deza), y uno se pone en manos de los integrantes de una cofradía. Tan sólo uno se publica en latín, muy culto (Cámara), mientras que el resto se da a conocer en castellano.

Estos catecismos ven la luz en un momento en que el Renacimiento está pujando con toda su fuerza por emerger a la superficie. Se dan a conocer obras literarias que son reflejo de nueva sensibilidad. En 1479 aparecen las Coplas a la muerte de su padre, de Jorge Manrique; en 1486, Hernando del Pulgar da a conocer Claros varones de Castilla. Poco después, 1492, se difundió la Gramática castellana, de Nebrija; Juan del Encina publicó su Cancionero en 1496, y Fernando de Rojas, la Comedia de Calixto y Melibea al año siguiente. Algo más lejano en el espacio, Erasmo ofrece a la consideración pública sus Adagiorum collectanea en 1500, y años después, en 1503, el célebre Enchiridion militis christiani.

Es verdad que la cartilla que promulga Cisneros para Toledo tiene muchos puntos en común con otras cartillas, anteriores y posteriores. Pero esta cartilla no va más allá, como posible elemento dinamizador de la época. De la misma forma, el catecismo que Diego de Deza inserta en el Missale giennense debe ser entendido e insertado en la corriente que desde el concilio de Valladolid de 1322 se repetía una y otra vez en diversos lugares; y eso antes y después de la publicación efectuada para la diócesis de Jaén. Pero tampoco se percibe como motor del que le sigue en cronología, ni que haya sido movido por alguno de los que le precedieron. 
Pero en los otros tres catecismos más amplios, que están en castellano, el de la Declaración, el de Talavera, y el de la cofradía de la Candelaria, sí es posible espigar una nueva soltura en el empleo de la lengua, que en cada caso, ha de ser vista como nuevas formas que emergen de un castellano más y más consolidado. El empleo del idioma que es posible apreciar en los catecismos es culto en general. Es la transición al Renacimiento que emerge imparable.

Cierto que en todos los casos están condicionados, a la hora de expresarse, por la necesidad de ofrecer la genuina fe, y de hacerlo con precisión. En sus formas literarias se ven requeridos por expresiones tradicionales, de raigambre medieval, en las que había cristalizado la exposición de la fe hasta ese momento. Pero se percibe un enriquecimiento literario naciente, no tan anclado en el pasado, especialmente en las frases o los párrafos que no repiten un formulario, sino que ofrecen con soltura una explicación de lo que constituye la fe.

Por otro lado, aunque haya sido publicado en latín, la amplia cultura que demuestra Alfonso de Cámara y las muy numerosas citas de unos y otros autores, no dan pie para pensar que en el momento de su publicación se esté pasando al sentir del Renacimiento. Esto se debe sobre todo a que apela a la cultura clásica, bíblica, patrística y teológica, sobre la que está construido. Si se le hiciera desaparecer la fecha, habría que ubicarlo, sin problemas, en la tradición catequética que desde finales del medievo se prolonga en el siglo XVI. Ni siquiera las numerosas citas y referencias de la biblia llevan a pensar en un cristianismo evangélico, como el que propiciaba Erasmo en sus primeras obras por los mismos años. La biblia es entendida como fuente de verdad, que confirma y sustenta las explicaciones que se contienen en los catecismos.

Otros tres catecismos apelan a la biblia, se inspiran en bastantes enseñanzas y reproducen su texto (Declaración, Cámara, Candelaria). Acaso, sin manifestarlo de manera rotunda, es posible percibir en ellos el gusto por el retorno a las fuentes, y a las fuentes bíblicas en particular. Desde luego, la citan con bastante frecuencia, aunque la intensidad sea diferente en cada caso.

Pero en ninguno de los catecismos examinados hay referencias, o al menos insinuaciones, a colectivos que precisaran formación cristiana, como eran los judíos, musulmanes o indios, todos ellos presentes en el pen- 
samiento común en el momento en que los catecismos aparecieron; al excluir estos grupos, no queda más que pensar en los cristianos de toda la vida, en los cristianos viejos, precisados de formación en su propia religión; están redactados para esto.

Tampoco se hace alusión alguna a las nuevas tendencias que están surgiendo en la sociedad, con una burguesía pujante, unas compañías mercantiles que acaparan dinero y riquezas, y que podían quebrantar los derechos de otros más débiles (nuevas formas de incumplir los mandamientos, de acaparar poder, de lesionar los intereses del prójimo).

\section{Los versos}

En un artículo, no suele ser frecuente una prolongación, y menos en uno no demasiado extenso. Pero a lo largo del mismo ha salido una y otra vez el uso de los "versos" que hacen algunos de estos catecismos, especialmente Alfonso de Cámara, y no se puede dejar pasar la ocasión para dar a conocer este subsidio para la catequesis ${ }^{18}$.

Acaso es demasiado calificarlo de "subsidio", y quizá podría entenderse mejor como un estorbo para quienes no sabían latín. Como todo el texto de Cámara está en latín, los versos no desentonan; en cambio, en los otros catecismos redactados en castellano no se entiende muy bien su uso, si no es como un residuo de la catequesis medieval que se resistía a desaparecer. Ahora bien, su pervivencia insistente, cuando ya se impone el castellano, es una muestra consolidada de lo muy arraigados que estuvieron en la catequesis medieval. Es probable que tuvieran la función de recordatorio; pero no hay más remedio que reconocer que cada vez eran menos entendidos, y que hubieron de ceder su puesto a las enumeraciones y formularios castellanos, puesto que el esfuerzo de aprenderlos para luego repetirlos de memoria, y poder llegar a captar su sentido era mucho mayor que el aprendizaje de un formulario sencillo en la lengua hablada a diario.

La variedad aparece también en la propia métrica: unos versos siguen la métrica latina, otros muestran su rima como hemistiquios; hay otros que

${ }^{18}$ Ya mostré una variedad notable de versos medievales en L. REsINEs, La catequesis... , 28-40. 
ya buscan la rima castellana en pareados; y otros carecen de toda clase de medida normativa. De ahí que denominarlos como versos es acomodarse a una denominación que se repetía de tiempo atrás, y debe ser aceptada con mucha amplitud. Todavía en el siglo XVI, se repitieron algunos de estos versos en otros catecismos posteriores como residuos de un pasado que se desvanecía.

Sigo el orden en que aparecen en el Libellum de Doctrina Christiana de Alfonso de Cámara.

Artículos de la divinidad (f. 178v)

Articulus primus monstrat quod sit unus deus

El artículo primero muestra que hay un

In patrem sequens dicit credere debes

Dios único.

El siguiente dice que debes creer en el Padre

Tertius in natum te cogit credere christum

Quartus te cogit in sanctum credere pneuma.

Credas in quinto deitatem cuncta creasse.

Sextus ait crede dominus peccata remittet.

Omnes surgemus septenus dicit aperte ${ }^{19}$.

El tercero te lleva a creer en el Hijo,

Cristo.

El cuarto te impone creer en el Espíritu Santo.

El quinto [es] que creas que la divinidad creó todo.

El sexto enseña: cree [que] Dios perdona los pecados.

El séptimo enseña con claridad que todos resucitaremos.

Artículos de la humanidad (f. 179v)

Conceptus, natus, passus, descendit ad ima.

Surgit et ascendit; veniet discernere cuncta $^{20}$.

Concebido, nacido, padeció, descendió al infierno

Resucitó y ascendió; vendrá a juzgar a todos.

Los apóstoles, autores de los artículos (f. 180r)

Articuli fidei sunt bis sex corde tenendi

Hay doce artículos de fe para aceptarlos de corazón

${ }^{19}$ En la versión de Gil de Albornoz, la composición dispone de un verso más al final: "Tunc dabitur pena malis, rrequies quoque justis" (= Entonces se les dará castigo a los malos, así como descanso a los justos). Con pequeñas variantes este verso figura en los otros catecismos indicados. (Ver Resines, Luis, La Catequesis ..., 29-30.

${ }^{20}$ Estos versos también figuran en ANÓNIMO, Orationes al plenum colectas, así como en el Sacramental de Clemente Sánchez de Vercial. 
Quos christi socii docuerunt pneumate pleni

Credo deum patrem petrus inquit cuncta creantem

Andreas dicit ego credo jesus fore christum

Conceptum natum iacobus, passusque ioannes

Inferos philippus fregit, thomasque reuiuit

Scandit bartholomeus, veniet censere matheus

Pneuma minor iacobus, simon peccata remittet

Restituet iudas carnem, vitamque mathias.

Ergo constanter credas ac indubitanter

Que docet ecclesia romana petra solidata

Secus non poteris fieri salvus nec sanctus heresi.

Sacramentos (f. 192r)

Abluo, firmo, cibo, piget, uxor, ordinat, vngit.

Mandamientos de Dios (f. 192v)

In tabulis binis $\mid$ lex est depicta petrinis Unum cole deum, | ne iures vana per illum

Sabbata sanctifices, | charos venerare parentes

Noli de cede notari, | noli mechari

Furta cave fieri. | Non sis testis nisi veri

Non cupias nuptas, | nec queras res alienas. que enseñaron los discípulos de Jesús, llenos de Espíritu .

Pedro dijo: creo en dios padre creador de todo;

Andres expresó: yo creo que Jesús era el Cristo;

Santiago, que fue concebido y nació; Juan, que padeció;

Felipe, que aniquiló el infierno; Tomás, que revivió;

Bartolomé, que ascendió; Mateo, que vendrá a juzgar;

Santiago menor, en el Espíritu; Simón: perdona los pecados;

Judas: revivirá la carne; Matías, y en la vida [eterna].

Por tanto, has de creer constantemente y sin dudas

Lo que enseña la iglesia romana edificada sobre piedra.

Si no, no podrás salvarte, ni protegerte de herejías.

Me bautizo, confirmo, alimento, se arrepiente, se casa, se ordena, se unge.

La ley está escrita en dos tablas pétreas. Adora un dios único, no jures por él en vano;

Santifica el sábado, respeta a tus queridos padres;

No se te conozca por una muerte, rehúsa fornicar;

Guardate de hacer robos. No testifiques más que la verdad;

No desees a las casadas, ni ansíes bienes ajenos. 
Pecados mortales (f. 195v)

Laudis amore tumens, miseraque cupidine auarus

inuidus, iracundus, iners, humosus, amator.

Pecado original y venial (f. 195v)

Sint omnia delicta | triplici nomine dicta

Est primo peccatum | nobis ab origine natum

Est grave mortale, | leuius fertur veniale

Cum baptizamur | ab origine purificamur

Necnon peccato | quodcumque sit, ante patratos

Sed cum peccamus | graviter post nos maculamus

Deletur tamen sacramentis scelera cunta.

Dones del Espíritu Santo (f. 206r)

Donis implere procura pneumatis alma

Esto timens, pius atque sciens, factis bene consul

Hic intellectus sapientia dona dei sunt fortisque.

Bienaventuranzas (f. 207v)

Sis bene dotatus, | vt sis in fine beatus

Sis pauper, mitis, flens, | sitiens ius, miserator

Mundus, pacificus, | sic vult mundi creator.

Per septem merita | dant tot premia magna

Pauper enim regnat, | mitis possesor habundat
Ansioso de ser alabado, avaro de deseo perecedero, ${ }^{21}$

envidioso, iracundo, perezoso, comilón, lujurioso.

Todos los pecados se conocen con tres nombres.

El primero, el pecado nacido en nosotros desde el principio;

[El otro] es grave, mortal; [el tercero] es venial, más leve.

Al bautizarnos nos purificamos del original,

Y de cualquier pecado cometido antes.

Después, al pecar con gravedad nos

vamos manchando;

Pero con los sacramentos desaparecen todos los delitos.

Procura llenar tu alma de dones del Espiritu,

Sé temeroso, piadoso y sabio, aconsejate bien al actuar,

inteligente, prudente y fuerte: estos son dones de Dios.

Adquiere un buen tesoro, y serás feliz al morir:

Sé pobre, compasivo, arrepentido, justo, misericordioso,

Limpio, pacífico, como quiere el creador del mundo.

Por estos siete méritos dan tan grandes premios:

El pobre reina, el compasivo abunda en bienes,

21 "Miseraque cupidine auarus" lo he traducido por "avaro de deseo perecedero", dando a "misera" el valor de lo miserable, lo despreciable. 
Flens consolatur, | sitiens justum satiatur

Fit pietasque piis |dominum mundusque videbit

Est quoque pacificus | domini proles amicus.

Obras de misericordia espirituales (f. 208r)

Consule, carpe, doce, solare, remitte, fer, ora.

Obras de misericordia corporales (f. 208r)

Visito, poto, cibo, redimo, tego, colligo, condo.

Sentidos (f. 209r) ${ }^{22}$

Vissus, odoratus, cum gustu, tactus et Vista, olfato, con gusto, tacto y oídos. auris.

Sentidos (de Bernardo de Custodia, f. 209r) $)^{23}$

Gustus, odoratus, | auditus, visio, tactus

Per te claudantur, | ne sordes ingrediantur.

Sobre María, nuestra señora (f. 214r) ${ }^{24}$

Angelus aduenit cum virgo fuit duodenis

Vixit cum christo terdenis et tribus annis

Post mortem christi nouem permansit in orbe.

Sobre la edad de la virgen (f. 214r)

Virgo parens vixit sexaginta cum tribus annis
El que llora es consolado, quien desea justicia la obtiene,

La piedad es para los piadosos, y el sencillo verá a Dios,

Y el pacífico es amigo de los fieles del Señor.

Aconseja, disculpa, enseña, consuela, perdona, soporta, reza.

Visito, doy bebida, alimento, redimo, visto, acojo, entierro.

Gusto, olfato, oído, vista, tacto:

Conservalos cerrados, y no te invadirá la maldad.

El ángel llegó cuando la virgen tenía doce años;

Vivió con Cristo otros treinta y tres años;

Tras la muerte de Cristo permaneció otro nueve en la tierra.

La virgen madre vivió sesenta y tres años:

${ }^{22}$ Exactamente igual en el texto de la Declaración, f. 112v.

${ }^{23}$ El mismo Alfonso de Cámara proporciona dos series de versos sobre los sentidos, y para la segunda señala el autor de donde los ha tomado.

${ }^{24}$ También Alfonso de Cámara reproduce dos versiones sobre la edad de María. Se limita a reproducirlas sin entrar en la diferencia sobre el número de años de su vida (54 o 63 respectivamente). 
Quattuor atque decem fuit in partu benedicta

Vixit cum filio triginta cum tribus annis

Sexque decem annis sed post hec astra subiuit.
A los catorce fue bendita con su maternidad;

Convivió con su hijo durante treinta y tres años;

Y diez y seis años después fue llevada al cielo.

La fijeza de los versos, a la vez que su variedad, hizo posible que pervivieran tradiciones divergentes que manifestaban los mismos contenidos. Al igual que sucedió con las tradiciones particulares sobre qué apóstol había expresado cada frase del credo, también figuran muestras divergentes de algunos versos en las páginas de los otros seis catecismos analizados.

Catecismo de la Declaración

Mandamientos (f. 112r) ${ }^{25}$

Sperne deos, fugito perjura,

sabata santifica

Menospreçiar los dioses, fuyr los perjurios,

sit tibi patris et matris honor,

non sis ocisor, fur, mechus,

testis iniquus,

Guardar los domingos e las fiestas

Sea a ty honrra de tu padre y de tu madre

Non seas [matador], luxurioso, furtador e ladron

vicinique thorum,

Non seas testigo malo e mentiroso

rrem quam cavete suam

Esquiva el lecho de tu vecino e proximo

Esquiva toda cosa agena e la su codicia

Catecismo de la Declaración

Obras de misericordia espirituales (f.

113v)

Consule, castiga, solare, rremite, fer, ora, doce

Aconseja, corrige, consuela, perdona, soporta, reza, enseña.

Catecismo de Diego de Deza

Obras de misericordia corporales (f. 261r) Doy comida, doy bebida, acojo, visto, viPasco, poto, colligo, tego, visito, libero, sito, libro, entierro.

condo

${ }^{25}$ La traducción es la misma que proporciona el texto original. 


\section{Conclusión}

Nos encontramos, por tanto, en una década en la que, a medida que pasaron los años, se produjo una inusitada floración de catecismos, debido a que unas cuantas personas, con absoluta independencia entre sí, se pusieron a la tarea de elaborar cada uno su propio catecismo. Se perciben cambios, con el paso progresivo del latín al castellano, con el empleo residual de versos recapitulativos de raigambre medieval, sustituidos con ventaja para el aprendizaje por meros enunciados, formularios a secas que no precisan traducción.

El estilo de las expresiones deja paso a una lengua mejor configurada. La vieja fe cristiana se vierte en odres nuevos, con el firme propósito de llegar cada vez mejor a los hombres y mujeres de los nuevos tiempos que se barruntaban a finales del siglo XV.

Se produce el paso al Renacimiento, que se abre paso en los espíritus con otro estilo, otras miras, otra concepción. Es mucho lo que estos catecismos deben aún a la mentalidad medieval, en la que están anclados; pero a la vez es otra concepción la que se va abriendo espacio, la que está floreciendo, la que apunta con otra visión, que trata de responder a los nuevos tiempos que se avecinan. Con absoluta independencia entre sí, seis autores dan fe simultáneamente que se aproximan nuevos tiempos, para los cuales es preciso dar otras respuestas.

\section{Nota complementaria}

Terminado y corregido este artículo, la investigación ha arrojado información sobre otros tres catecismos que corresponden igualmente a esta década:

- InStRUCTIO de doctrina christiana, s. XV.| El Escorial: Monasterio, ms. d-IV-15, f. 91r-100r.

- [CREDO per Apostolos], ms. s. XIV-XV.| Madrid: BNE, ms. 9480.

- Los ARTículos de la fe, s. XV (?)| Madrid: BNE, en AlfONSO DE CÁmARA, Epythome..., 1496, (fuera de paginación); este último publicado en "Estudio Agustiniano" 55 (2020) 631-665.

Se confirma, pues, que se trata de una década asombrosa. 